Revista Brasileira de Agricultura Irrigada v.12, nº.3, p. 2702 - 2715, 2018 ISSN 1982-7679 (On-line)

Fortaleza, CE, INOVAGRI - http://www.inovagri.org.br

DOI: $10.7127 /$ rbai.v12n300873

Protocolo 873.18 - 22/01/2018 Aprovado em 13/07/2018

\title{
AMBIÊNCIA E BIOFERTIRRIGAÇÃO NA CULTURA DO FIGO
}

Francisco Limeira da Silva ${ }^{1}$, Thales Vínicius de Araújo Viana ${ }^{2}$, Geocleber Gomes de Sousa $^{3}$, Fátima Maria Martins Oliveira ${ }^{1}$, Benito Moreira de Azevedo², Giovana Lopes da Silva ${ }^{4}$

\section{RESUMO}

Objetivou-se, com este trabalho, avaliar os teores foliares de macronutrientes em plantas de figo adubadas com biofertilizante bovino cultivada em diferentes ambientes. $\mathrm{O}$ experimento foi conduzido na área experimental da Unidade de Ensino, Pesquisa e Extensão - UEPE, em Limoeiro do Norte, CE. A semeadura foi feita em vasos, utilizando-se, como substrato, um Cambissolo Vermelho Amarelo. O delineamento experimental foi o de blocos completos ao acaso, com parcelas subsubdivididas, com quatro repetições. As parcelas foram constituídas por três ambientes (pleno sol - PS, latada - LT e estufa - EST), e nas subparcelas, as quatro concentrações do biofertilizante bovino diluídas em água: $\mathrm{T}_{0}$ ( $0 \%$ de biofertilizante e $100 \%$ de água); $\mathrm{T}_{1}$ (20\% de biofertilizante e $80 \%$ de água); $\mathrm{T}_{2}$ (40\% de biofertilizante e $60 \%$ de água); $\mathrm{T}_{3}$ (60\% de biofertilizante e $40 \%$ de água) e a subsubparcela, os ciclos produtivos. Os macronutrientes analisados foram: N, P, K, Ca e Mg. A concentração de 60\% de biofertilizante bovino nas três épocas de avaliação aumentou os teores foliares de $\mathrm{N}, \mathrm{P}$ e K e reduziu os teores de Ca e Mg em plantas de figo nos diferentes ambientes de cultivo. As plantas de figo adubadas com o biofertilizante bovino estavam supridas em N, P e K, e deficiente em Ca e Mg durante as três épocas de avaliação nos diferentes ambientes de cultivo.

Palavras-chave: Ficus carica L., fertilizante orgânico, nutrição de plantas

\section{ENVIRONMENT AND BIOFERTIRRIGATION IN FIGO CULTURE}

\footnotetext{
ABSTRACT

The objective of this study was to evaluate leaf macronutrient content in biofertilized (with bovine fertilizer) fig plants when grown in different environments. The experiment was conducted at the experimental unit of Teaching, Research and Extension - UEPE in

${ }^{1}$ Doutor em Engenharia Agrícola, Prof. do IFCE, Campus de Umirim, e-mail: fco_limeira@yahoo.com.br

${ }^{2}$ Doutor em Engenharia Agrícola, Prof. da UFC, e-mail:thales@ufc.br;benitoazevedo@hotmail.com

${ }^{3}$ Doutor em Engenharia Agrícola, Prof. da UNILAB, e-mail:sousagg@unilab.edu.br

${ }^{4}$ Doutora em Ecologia e Recursos Naturais, Profa. IFMA, Campus Codó, e-mail:gisolos@hotmail.com
} 
Limoeiro do Norte, CE. The seeds were sown in pots, using Red-Yellow Cambisol as substrate. The experimental design was that of completely randomized blocks with splitsplit plots and four replications. The plots consisted of three environments (full sunlight - PS, trellis - LT and greenhouse - EST), the subplots consisted of four concentrations of water-diluted bovine biofertilizer: T0 (0\%fertilizer and 100\% water); T1 (20\% fertilizer and $80 \%$ water), T2 (40\% fertilizer and 60\% water), T3 (60\% fertilizer and $40 \%$ water) and the subsubplots consisted of the production cycles. Analyzed Macronutrients were: $\mathrm{N}, \mathrm{P}, \mathrm{K}, \mathrm{Ca}$ and $\mathrm{Mg}$. A 60\% concentration of bovine biofertilizer in the three evaluation periods increased leaf $\mathrm{N}, \mathrm{P}$ and $\mathrm{K}$ contents and reduced Ca and $\mathrm{Mg}$ levels in fig plants in the different environmental conditions tested. The biofertilized with bovine fig plants were supplied of $\mathrm{N}, \mathrm{P}$ and $\mathrm{K}$, and deficient in $\mathrm{Ca}$ and $\mathrm{Mg}$ during the three evaluation periods in the different environmental conditions tested.

Keyword: Ficus carica L., organic fertilization, mineral nutrition

\section{INTRODUÇÃO}

Originária da Ásia e da Síria, na região mediterrânea, a figueira (Ficus carica L.) é uma das mais antigas frutíferas cultivadas no mundo. Leonel e Tecchio (2010) relataram que a cultura da figueira é interessante para o Brasil, pois este é, atualmente, o segundo maior exportador de frutos in natura do mundo, e, devido à possibilidade de a produção brasileira coincidir com a entressafra do mercado mundial, no hemisfério Norte.

Essa frutífera apresenta excelente adaptação a diferentes climas e é cultivada tanto em regiões subtropicais quentes, como em regiões de clima temperado (DALASTRA et al., 2009). O cultivo da figueira em regiões de clima quente tem-se mostrado uma alternativa viável em face do bom desenvolvimento das plantas e de boas produtividades. No entanto, o cultivo em ambiente protegido tem aumentado consideravelmente nas últimas décadas, não só no Brasil, mas, também em todo o mundo (SILVA et al., 2003).

De acordo com Reis et al. (2012), o cultivo em ambiente protegido visa aumentar a produtividade e melhorar a qualidade dos produtos agrícolas e, assim, amenizar as variações sazonais na produção, o que é possível devido ao fato da proteção diminuir os efeitos adversos do excesso de chuva, da alta incidência de radiação e dos extremos de temperatura do ar.
As exigências nutricionais com fonte orgânica para a cultura da figueira ainda está em ascensão no meio científico. Uma alternativa viável pode ser a substituição de fertilizantes minerais por insumos orgânicos de origem vegetal e animal (CAVALCANTE et al., 2012; SANTOS et al., 2014). Leonel e Damatto Júnior (2008) constataram que o esterco de curral supriu nutricionalmente as plantas de figo durante a fase de frutificação indicando resultados positivos com relação à produção de frutos. Já Cavalcante et al. (2010) trabalhando com esterco de frango, constataram maiores teores foliares de fósforo e o esterco de caprino maior acumulação de potássio em folhas de quiabeiro.

Outra fonte orgânica que vem sendo utilizada para substituir parcialmente os fertilizantes minerais é o biofertilizante. Esse insumo é um adubo orgânico líquido produzido em meio aeróbico ou anaeróbico a partir de uma mistura de material orgânico (esterco fresco) e água. No entanto, a composição química do biofertilizante varia conforme o método de preparo, o tempo de decomposição, a população microbiológica, temperatura e $\mathrm{pH}$ do composto, bem como o material que o origina (MARROCOS et al., 2012).

O objetivo deste trabalho foi avaliar os teores foliares de macronutrinetes em plantas de figo adubadas com biofertilizante bovino cultivada em diferentes ambientes. 


\section{MATERIAL E MÉTODOS}

O experimento foi conduzido em três ambientes de cultivo: pleno sol (PS), latada (LT) e estufa (EST) na Unidade de Ensino, Pesquisa e Extensão (UEPE) do IFCE, Campus de Limoeiro do Norte, Ceará, a $05^{\circ} 10^{\prime} 38^{\prime}$ ' de latitude Sul; $38^{\circ} 00^{\prime} 21$ e altitude de 144,6 m. Segundo a classificação de Köppen, a área do experimento está localizada numa região de clima BSw'h', ou seja, semiárido, quente, com chuvas no verão-outono, sendo o trimestre março-maio o período mais chuvoso e o período julho-dezembro o mais seco.

O primeiro ambiente foi do tipo estufa comercial do tipo capela e com cobertura de polietileno de baixa densidade, com $150 \mu \mathrm{m}$ de espessura, com filtro anti UV e as laterais fechadas com tela, com malha de $3,0 \mathrm{~mm}$. O segundo ambiente foi do tipo latada, com as laterais abertas, com estrutura de colunas e caibros de madeiras, disponíveis na região. O terceiro ambiente foi a pleno sol. Todos os ambientes apresentavam as dimensões: comprimento 32,0 m e largura 6,4 m; altura da parte central 4,20 m e 3,0 m de pé direito.

As condições ambientais durante a condução do ensaio foram monitoradas por uma estação meteorológica automática situada a $50 \mathrm{~m}$ da área experimental. No interior dos ambientes de cultivo protegido (latada e estufa), o monitoramento foi realizado por meio de termohigrômetro HOBO U12 Temp/RH Light/External Data Logger. Os dados de temperatura média do ar e as umidades relativas mensais encontram-se na Tabela 1.

Tabela 1. Valores médios de temperatura média do ar e umidade relativa durante a condução do experimento

\begin{tabular}{cccccccc}
\hline \multirow{2}{*}{ Ano } & Meses & \multicolumn{2}{c}{ Temperatura média do ar $\left({ }^{\circ} \mathrm{C}\right)$} & \multicolumn{3}{c}{ Umidade relativa (\%) } \\
\cline { 2 - 7 } & & Pleno sol & Latada & Estufa & Pleno sol & Latada & Estufa \\
\hline 2010 & out/dez & 28,06 & 29,3 & 30,26 & 29,76 & 30,03 & 29,86 \\
2011 & jan/jun & 27,28 & 28,38 & 29,2 & 28,78 & 28,93 & 28,88 \\
\hline
\end{tabular}

O solo utilizado como substrato é classificado como CAMBISSOLO VERMELHO AMARELO, textura francoargilo-arenoso (EMBRAPA, 2013), com densidade do solo de $1,3 \mathrm{~g} \mathrm{~cm}^{-3}$. Foram coletadas amostras composta na profundidade de 0-40 $\mathrm{cm}$ para determinação dos atributos químicos, indicados na Tabela 2, conforme Embrapa (1997).

Tabela 2. Caracterização química do solo antes da aplicação dos tratamentos.

\begin{tabular}{|c|c|c|c|c|c|c|c|c|c|c|c|}
\hline $\begin{array}{l}\text { PROF } \\
(\mathrm{cm})\end{array}$ & $\begin{array}{l}\text { M.O } \\
\text { g Kg }^{-1}\end{array}$ & 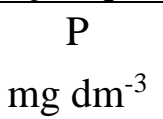 & $\mathrm{N}$ & K & $\begin{array}{c}\mathrm{Ca} \\
\mathrm{g} \mathrm{kg}^{-1}\end{array}$ & $\mathrm{Mg}$ & $\mathrm{Na}$ & $\mathrm{pH}$ & $\begin{array}{l}\mathrm{V} \\
\%\end{array}$ & $\begin{array}{c}\text { PST } \\
\%\end{array}$ & $\begin{array}{l}\text { CEes } \\
\mathrm{dS} \mathrm{m}^{-1}\end{array}$ \\
\hline $0-40$ & 16,98 & 0,057 & 0,024 & 0,009 & 1,225 & 0,174 & 0,067 & 6 & 84 & 5 & 1 \\
\hline
\end{tabular}

PROF= profundidade; M.O= matéria orgânica; $\mathrm{PST}=$ Porcentagem de sódio trocável; CEes= condutividade elétrica do extrato de saturação; V=saturação por base

A partir das análises químicas do solo (Tabela 2), procurou-se fornecer no tratamento com maior concentração (60\%) a recomendação máxima para $\mathrm{N}, \mathrm{P}$ e K proposta por Tomé Júnior 1997)
(Tabela 3). Considerou-se também, nesses cálculos, a densidade global do solo e uma população de $4.444,4$ plantas $\mathrm{ha}^{-1}$ para um espaçamento de $1,50 \mathrm{~m} \mathrm{x}$ $1,50 \mathrm{~m}$.

Tabela 3. Quantidade dos nutrientes recomendada para o figo Roxo de Valinhos, presentes no solo e necessidades de complementação nutricional 


\begin{tabular}{|c|c|c|c|}
\hline \multirow[t]{2}{*}{ Características químicas } & \multicolumn{3}{|c|}{ Nutriente } \\
\hline & $\mathrm{N}$ & $\mathrm{P}_{2} \mathrm{O}_{5}$ & $\mathrm{~K}_{2} \mathrm{O}$ \\
\hline \multirow[t]{2}{*}{ Recomendação } & \multicolumn{3}{|c|}{$\left(\right.$ g planta $^{-1}$ ) } \\
\hline & 36,6 & 90 & 22 \\
\hline \multirow[t]{2}{*}{ Presentes no solo (PS) } & \multicolumn{3}{|c|}{$\left(\mathrm{g} \mathrm{kg}^{-1}\right)$} \\
\hline & 0,024 & 0,057 & 0,009 \\
\hline $\begin{array}{l}\text { Densidade do solo } \\
\text { VSEP }\end{array}$ & & $\begin{array}{r}1,3 \mathrm{~g} \mathrm{k} \\
600 \mathrm{I}\end{array}$ & \\
\hline \multirow[t]{2}{*}{ FTS (PS*DS*VSPE) } & & g plant & \\
\hline & 18,72 & 44,46 & 7,02 \\
\hline \multirow[t]{2}{*}{ NCN } & & g plant & \\
\hline & 17,88 & 44,4 & 14,98 \\
\hline
\end{tabular}

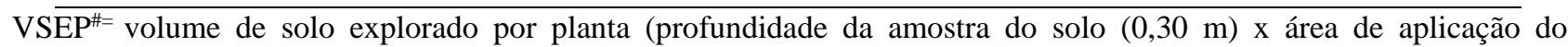
biofertilizante $\left(2 \mathrm{~m}^{2}\right)$ ); FTS= fornecimento total do solo; NCN= necessidade de complementação nutricional.

As mudas foram originadas de estacas de plantas matrizes da cultivar Roxo de Valinhos e transplantadas.

O delineamento experimental foi o de blocos completos ao acaso, com parcelas subsubdivididas, com quatro repetições. As parcelas foram constituídas por três ambientes (pleno sol - PS; latada - LT e estufa - EST), as subparcelas, as quatro concentrações do biofertilizante bovino diluídas em água nas seguintes concentrações: $\mathrm{T}_{0} \quad(0 \%$ de biofertilizante e $100 \%$ de água); $\mathrm{T}_{1}$ (20\% de biofertilizante e $80 \%$ de água); $\mathrm{T}_{2}$ (40\% de biofertilizante e $60 \%$ de água); $\mathrm{T}_{3}$ (60\% de biofertilizante e $40 \%$ de água) e as subsubparcelas, três épocas de avalição das plantas aos 60; 120 e 180 DAT.

O biofertilizante bovino foi preparado a partir de uma mistura de partes iguais de esterco fresco bovino e água sob fermentação aeróbia, durante 30 dias, em recipiente plástico (SOUSA et al., 2013). Os teores de nutrientes (N, P, K, Ca, Mg, S, Fe, Zn, Cu, Mn e Na) na composição química da matéria seca do biofertilizante, encontram-se na Tabela 4. As análises foram realizadas adotando-se as metodologias sugeridas por Malavolta et al. (1997).

Tabela 4. Características químicas do biofertilizante depois de diluído em água nas diferentes concentrações

\begin{tabular}{ccccccccccccc}
\hline \multirow{2}{*}{ Amostras } & \multicolumn{4}{c}{ Macronutrientes $\left(\mathrm{g} \mathrm{L}^{-1}\right)$} & \multicolumn{4}{c}{ Micronutrientes $\left(\mathrm{mg} \mathrm{L}^{-1}\right)$} \\
\hline & $\mathrm{N}$ & $\mathrm{P}$ & $\mathrm{K}$ & $\mathrm{Ca}$ & $\mathrm{Mg}$ & $\mathrm{S}$ & $\mathrm{Fe}$ & $\mathrm{Zn}$ & $\mathrm{Cu}$ & $\mathrm{Mn}$ & $\mathrm{Na}$ \\
\hline $\mathrm{T}_{1}$ & 0,14 & 0,22 & 0,25 & 0,11 & 0,06 & 0,05 & 15,5 & 0,02 & 0,02 & 1,86 & 45 \\
$\mathrm{~T}_{2}$ & 0,23 & 0,23 & 0,49 & 0,24 & 0,11 & 0,08 & 30,1 & 0,8 & 0,02 & 3,4 & 52 \\
$\mathrm{~T}_{3}$ & 0,4 & 0,32 & 0,68 & 0,38 & 0,17 & 0,12 & 44,38 & 2,38 & 1,06 & 5,28 & 60 \\
\hline
\end{tabular}

O emprego do biofertilizante, aplicado ao solo, nas diferentes concentrações se deu através da aplicação, quinzenal, de três litros por planta por um período de 15 meses, perfazendo, nas três avaliações, um total de 90 litros por planta. O fornecimento total de biofertilizante nas diferentes concentrações encontram-se na Tabela 5. 
Tabela 5. Fornecimento total de biofertilizante nas diferentes concentrações

\begin{tabular}{cccccc}
\hline Tratamentos & $\mathrm{N}$ & $\mathrm{P}_{2} \mathrm{O}_{5}$ & $\mathrm{~K}_{2} \mathrm{O}$ & $\mathrm{Ca}$ & $\mathrm{Mg}$ \\
\cline { 2 - 6 } $\mathrm{T}_{0}$ & 0 & 0 & 0 & 0 & 0 \\
$\mathrm{~T}_{1}$ & 12,6 & 19,8 & 22,5 & 9,9 & 5,4 \\
$\mathrm{~T}_{2}$ & 20,7 & 20,7 & 44,1 & 21,6 & 9,9 \\
$\mathrm{~T}_{3}$ & 36 & 28,8 & 61,2 & 34,2 & 15,3 \\
\hline
\end{tabular}

O sistema de irrigação localizada utilizado na condução do experimento foi do tipo gotejamento autocompensante com vazão de $4 \mathrm{~L} \mathrm{~h}^{-1}$. A lâmina de irrigação aplicada diariamente foi quantificada a partir da evaporação medida em um tanque classe “A”.

As coletas das folhas para avaliação dos teores foliares em macronutrientes (N, P, K, Ca e $\mathrm{Mg}$ ) do figo Roxo de Valinhos foram realizadas na época de pleno florescimento, ou seja, aos 60 dias após a pode formação (DAPf), a segunda em abril, aos 120 DAPf e a terceira poda realizada em junho, aos 180 DAPf. As folhas foram acondicionadas em sacos de papel previamente identificados e postas para secar em estufa com circulação de ar, a $65^{\circ} \mathrm{C}$, até massa constante.

As amostras após secas em estufa (folha) foram trituradas em moinho tipo Wiley, acondicionadas em sacos de papel devidamente identificados para determinação dos teores de N, P, K, Ca e Mg na matéria seca para avaliação do estado nutricional da cultura da figueira. Os teores de nitrogênio foram quantificados em soluções obtidas de extratos preparados por digestão sulfúrica pelo método micro-Kjeldahl (TEDESCO et al., 1995). Os teores de K foram obtidos por fotometria de chama, os teores de $\mathrm{P}$ por colorimetria (e os de $\mathrm{Ca}$ e $\mathrm{Mg}$ por espectrofotometria de absorção atômica Malavolta et al. (1997).

Os resultados foram submetidos à análise de variância e de regressão e as médias comparadas pelo teste de Tukey com $\mathrm{p}<0,05$, utilizando-se o programa SAEG/UFV.

\section{RESULTADOS E DISCUSSÃO}

O aumento das concentrações de biofertilizante bovino proporcionou uma superioridade nos teores de $\mathrm{N}$ na latada na primeira e terceira época de avaliação (Figura 1A; Figura 1C) e na estufa durante a segunda época de avaliação (Figura 1B). Cabe ressaltar que mesmo em estufas nãoclimatizadas, a acumulação de nutrientes superaram os valores obtidos em pleno sol. Ou seja, possivelmente na latada as plantas consomem menos água, diminui-se a lixiviação de nutrientes, há um melhor aproveitamento da radiação solar e consequentemente melhor desempenho na absorção de fotoassimilados pelo tecido vegetal. 

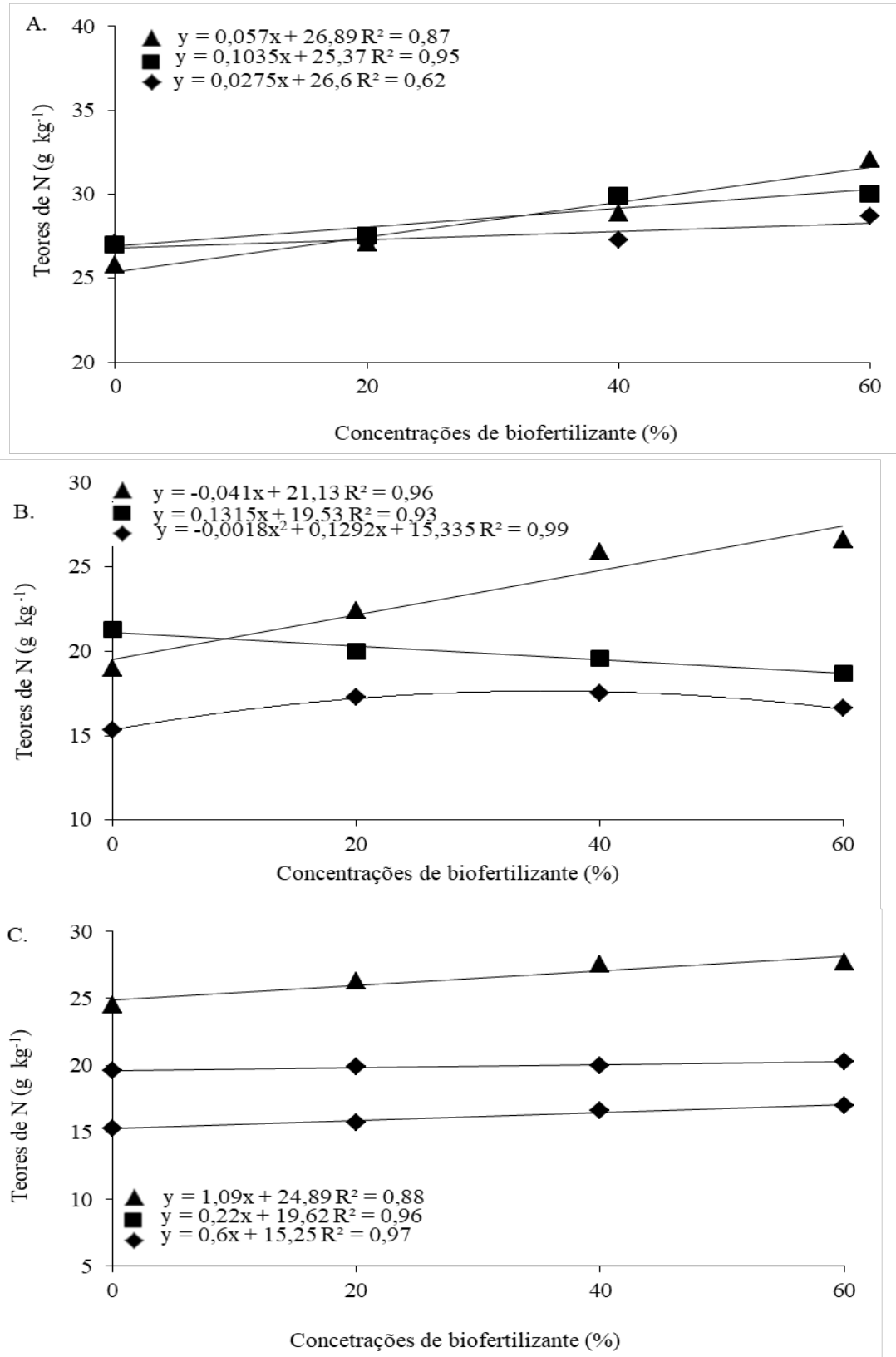

Figura 1. Teores de nitrogênio em plantas de figueira sob diferentes concentrações de biofertilizante bovino, em função da época de avaliação: A (60 DAT), B (120 DAT) e C (180 DAT) cultivada em diferentes ambientes: pleno sol ( - ), latada ( - ) e estufa (- )

Os resultados de análise foliar obtidos durante as épocas de avaliações indicaram que os teores de nitrogênio presente nas folhas se encontravam superiores ao padrão indicado para a cultura, que varia de 10 a $25 \mathrm{~g} \mathrm{~kg}^{-1}$ (BOARETTO et al., 2009). Resultados opostos ao desse estudo foram constatados por Leonel \& Damatto Júnior (2008), ao avaliarem efeitos do esterco de curral como fonte orgânico do solo na figueira. Esses autores encontraram 32 $\mathrm{g} \mathrm{kg}^{-1}$ de $\mathrm{N}$ em plantas adubadas com $100 \%$ da dose de $\mathrm{N}$.
Em outras frutíferas também foram constatados efeitos satisfatórios com utilização de fontes orgânicas na adubação, a exemplo de Cavalcante et al. (2012), trabalhando em condições de campo, constataram um aumento na concentração de $\mathrm{N}$ na cultura da pinha adubada com esterco bovino, e de Santos et al. (2017) utilizando biofertilizante bovino em mudas micropropagadas de bananeira prata catarina.

O período de maior incremento de $\mathrm{P}$ nas plantas de figo em função das concentrações de 


\section{AMBIÊNCIA E BIOFERTIRRIGAÇÃO NA CULTURA DO FIGO}

biofertilizante bovino foi aos 120 DAT. Nesse período o maior teor de $\mathrm{P}$ foi de $21 \mathrm{~g} \mathrm{~kg}^{-1}$ foi obtido na latada seguido do pleno sol e estufa (Figura 2B).
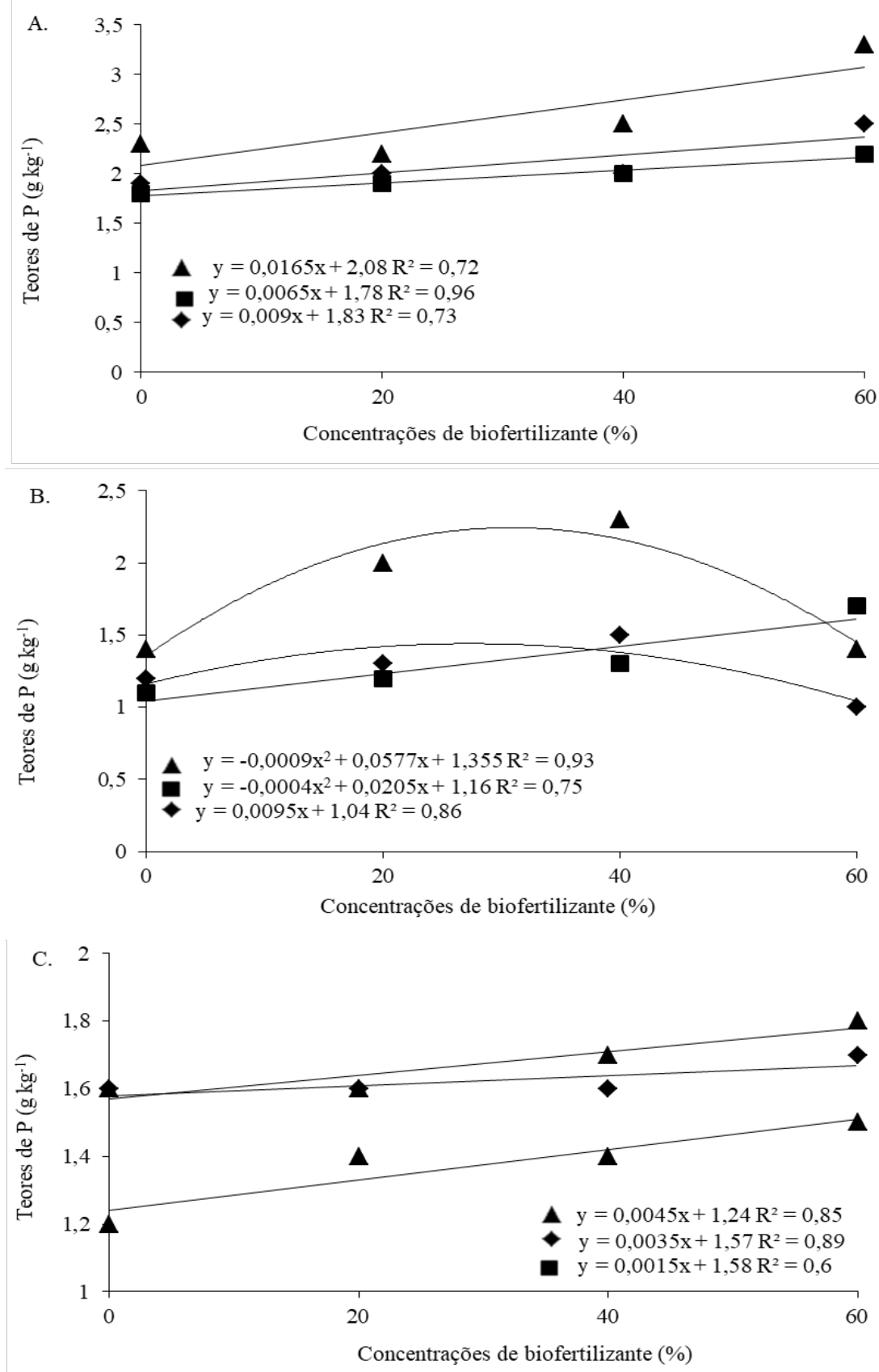

Figura 2. Teores de fósforo em plantas de figueira sob diferentes concentrações de biofertilizante bovino em função da época de avaliação: A (60 DAT), B (120 DAT) e C (180DAT) cultivada em diferentes ambientes: pleno sol ( ), latada ( ) e estufa ( )

Na primeira (60 DAT) e terceira (180 DAT) época de avaliação (Figura 2A; Figura 2C), as concentrações de biofertilizante bovino elevou os teores de $\mathrm{P}$ nos ambientes de cultivo estufa, pleno sol e latada, porém, em menor quantidade. Os teores médios de $\mathrm{P}$ encontrados nas folhas de figo foram de 1,8 a $3 \mathrm{~g} \mathrm{~kg}^{-1}$ entre as épocas e os ambientes de cultivo sob as diferentes concentrações de biofertilizante bovino, teor considerado adequado para a cultura (1 a $2 \mathrm{~g} \mathrm{~kg}^{-1}$ ), (BOARETTO et al., 2009).

Essa variação de teores de $\mathrm{P}$ em plantas de figo durante as épocas de avaliação nos diferentes ambientes de cultivos pode está relacionado ao período de amostragem e ao 
deslocamento de P para a formação de flores e produção dos frutos (LEONEL; TECCHIO, 2009). Ao analisar os teores foliares de plantas de figo em pleno florescimento das plantas, Leonel e Damatto Júnior (2008), registraram valores similares ao desse estudo $\left(3,4 \mathrm{~g} \mathrm{~kg}^{-1}\right)$.

Cardoso et al. (2010) trabalhando em ambiente protegido sob adubação orgânica com fibra de casca de coco reutilizada, constataram teores foliares menores em relação ao nosso estudo $(0,43$ de $\mathrm{P}$ em folhas de melão. Ao contrário do observado no presente estudo, Macedo (2008) avaliando o efeito da adubação orgânica sobre a nutrição do figo Roxo de Valinhos em um ARGISSOLO VERMELHO AMARELO, não encontraram efeito significativo sobre os teores foliares de P.
$\mathrm{O}$ acúmulo de $\mathrm{K}$ nas folhas respondeu acentuadamente ao aumento das concentrações de biofertilizante bovino na primeira época de avaliação (60 DAT) apenas na latada (Figura 3A). Já na segunda (120 DAT) e terceira (180 DAT) época de avaliação (Figura 3B; Figura 3C), as concentrações de biofertilizante bovino elevaram os teores de $\mathrm{K}$ de forma linear crescente na latada e a pleno sol e de forma quadrática na estufa, obtendo nesse último ambiente um valor máximo de 26,43 $\mathrm{g} \mathrm{kg}^{-1}$ para uma concentração de $30,27 \%$ de biofertilizante.

Os teores médios de $\mathrm{K}$ encontrados nas folhas de figo nos diferentes ambientes e época de avaliação (12 e 28 g $\mathrm{kg}^{-1}$ ) foram considerados adequados para a cultura (10 a 30 $\mathrm{g} \mathrm{kg}^{-1}$ ) (Boaretto et al., 2009). 

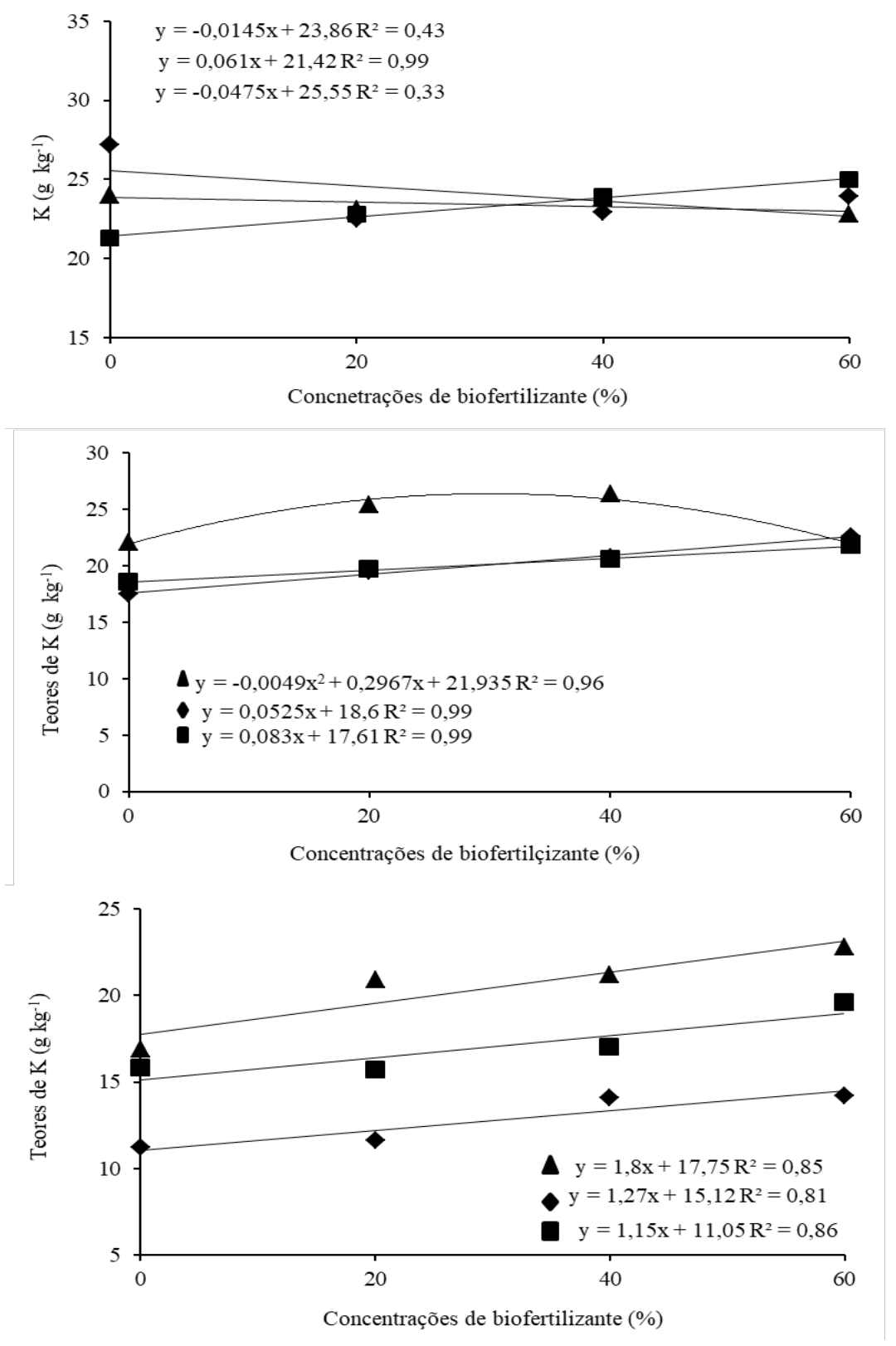

Figura 3. Teores de potássio em plantas de figueira sob diferentes concentrações de biofertilizante bovino em função da época de avaliação: A (60 DAT), B (120 DAT) e C (180DAT) cultivada em diferentes ambientes: pleno sol ( ), latada ( ) e estufa ( )

Cabe ressaltar que a variação de teores de $\mathrm{K}$ nos diferentes ambientes e épocas de avaliação pode está relacionada com a conclusão de Brizola et al. (2005), ao verificarem que a variação nos teores de K nas folhas de figo durante anos agrícolas consecutivos, poderiam ser atribuídas às diferenças de estádios fisiológicos da planta. Ou seja, a planta pode se adapta na distribuição desse elemento mineral entre fotoassimilados (folha e fruto).
Comportamento semelhante foi observado por Leonel e Damatto Júnior (2008), que avaliando o estado nutricional de plantas de figo sob adubação com esterco de curral, também observaram influência significativa nos teores foliares de $K$. Tendência semelhante foi observada por Macedo (2008) ao investigar a adubação do figo com composto orgânico (21 $\mathrm{g} \mathrm{kg}^{-1}$ de K) e por Viana et al. (2013) em plantas de meão (24 g kg-1 de K). 
A acumulação de cálcio sob as diferentes concentrações de biofertilizante bovino na primeira avalição foi maior na estufa, seguido do pleno sol e latada (Figura 4A). Na segunda época de avaliação, os teores de cálcio foram maiores na latada, seguida da estufa e a pleno sol, enquanto na terceira foi maior no pleno sol, depois a latada e estufa (Figura 4B; Figura 4C).

Os teores de cálcio encontrados nas folhas na primeira época de avaliação nos três ambientes e na segunda época de avaliação em pleno sol e na terceira época avaliação na estufa, estão abaixo da faixa descrita por Boaretto et al. (2009) como adequada à figueira. Os altos teores de potássio presentes no solo e nas diferentes concentrações de biofertilizante podem ter influenciado negativamente a absorção de cálcio pelas plantas (Cavalcante et al., 2012).
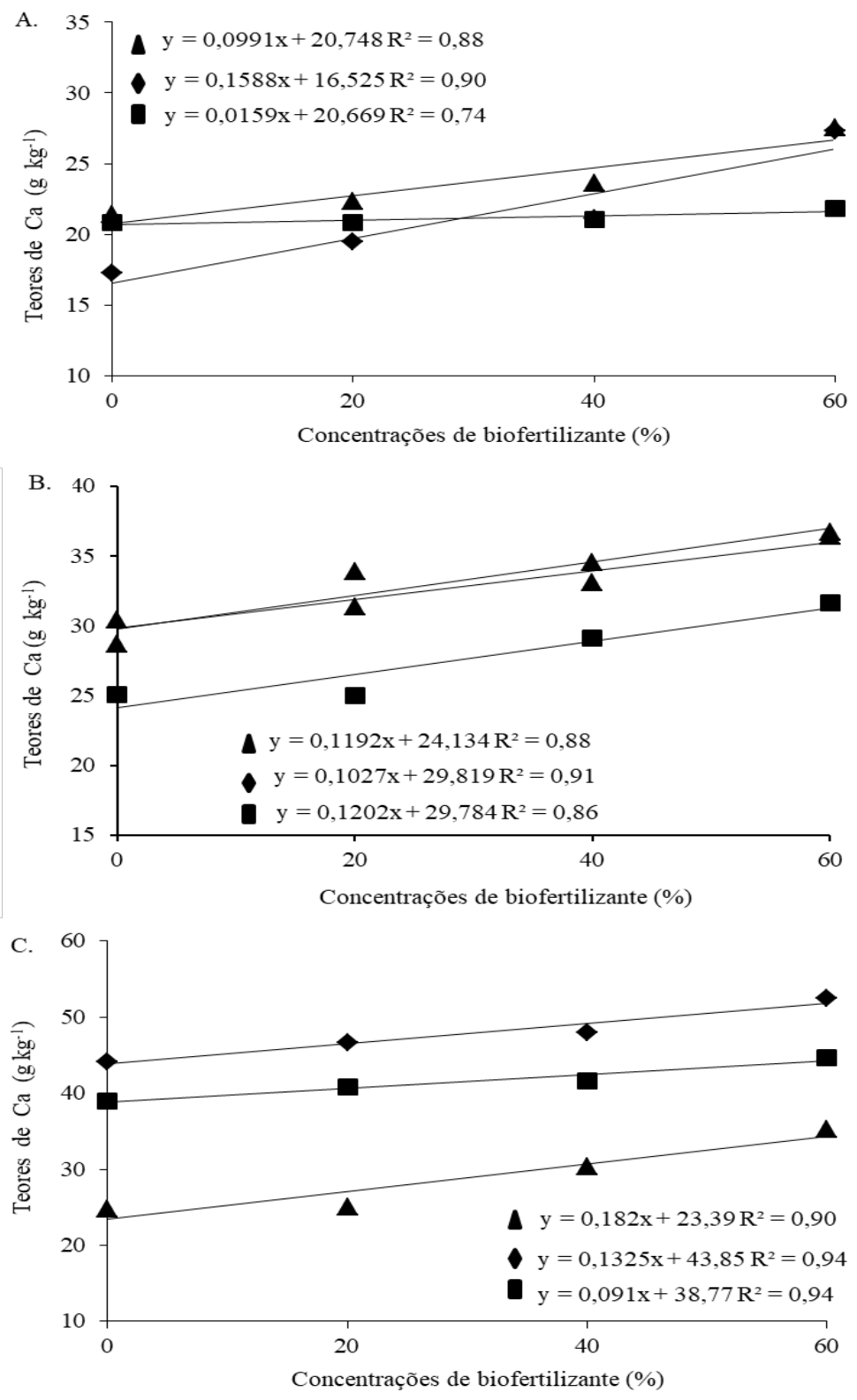

Figura 4. Teores de cálcio em plantas de figueira sob diferentes concentrações de biofertilizante bovino em função da época de avaliação: A (60 DAT), B (120 DAT) e C (180 DAT) cultivada em diferentes ambientes: pleno sol ( ), latada ( ) e estufa ( ) 
Trabalhando em condições de campo, Leonel e Damatto Júnior (2008) também encontraram valores abaixo (13g) do recomendado para a cultura do figo ao utilizar esterco de curral como fonte de adubação.

Estudos com outras frutíferas mostraram similaridade com os resultados obtidos nessa pesquisa. Moreira et al. (2012) registraram redução nos teores foliares de cálcio em plantas de pitaia vermelha sob adubação orgânica. Semelhantemente, Cavalcante et al. (2012) avaliando o efeito da adubação orgânica a base de esterco de bovino sob os teores foliares em plantas de pinheira, observaram uma redução nos teores de cálcio.

$\mathrm{O}$ aumento dos teores foliares de $\mathrm{Mg}$ ocorreu de forma linear em função das concentrações de biofertilizante bovino entre os ambientes estudados (Figura 5). Na primeira avalição a maior acumulação de $\mathrm{Mg}$ foi na estufa, seguido pela latada e pleno sol (Figura 5A). Durante a segunda avaliação (Figura 5B) os teores de $\mathrm{Mg}$ foram maiores na latada, pleno sol e estufa, enquanto, na terceira avaliação (Figura 5C) foram no pleno sol, latada e estufa.

Os valores médios de Mg encontrados no tecido foliar nas diferentes épocas de avaliação e ambientes ficaram abaixo da faixa considerada adequada para a cultura do figo (7,5 a $\left.10 \mathrm{~g} \mathrm{~kg}^{-1}\right)$, como relatam Boaretto et al. (2009). Apesar do comportamento linear, os baixos teores de $\mathrm{Mg}$ pode ser reflexo dos maiores teores de $\mathrm{K}$ presentes nas diferentes concentrações de biofertilizante bovino e no solo que podem ter reduzido a absorção de magnésio, em função de competição pelos sítios de absorção (MARTINS et al., 2013). 

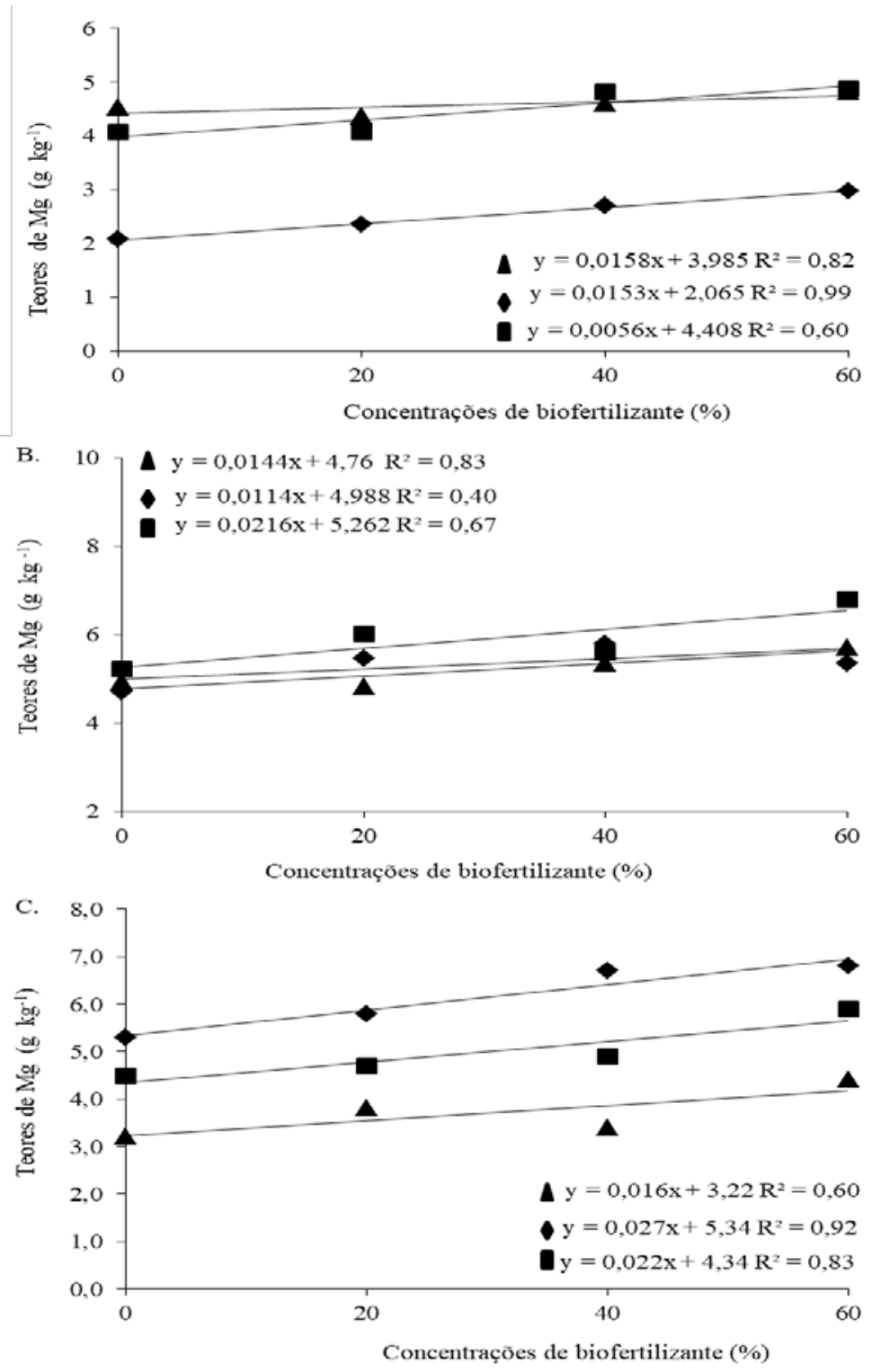

Figura 5. Teores de magnésio em plantas de figueira sob diferentes concentrações de biofertilizante bovino em função da época de avaliação: A (60 DAT), B (120 DAT) e C (180DAT) cultivada em diferentes ambientes: pleno sol ( ), latada ( ) e estufa ( )

Resultados oposto ao desse estudo foram observados por Leonel \& Damatto (2008) trabalhando em condições de campo com adubação orgânica aplicada na cultura do figo. Ou seja, os autores registraram teores foliares de $\mathrm{Mg}$ variando entre 12 e $15 \mathrm{~g} \mathrm{~kg}^{-1}$. Esse efeito pode está relacionada à fonte orgânica aplicada (esterco de curral) no campo.

É pertinente ressaltar que outros pesquisadores, a exemplo Cardoso et al. (2010) e Menezes et al. (2012), também constataram efeitos satisfatórios com utilização de esterco bovino e biofertilizante bovino, nos teores foliares de $\mathrm{Mg}$ na cultura do meloeiro e do maracujazeiro-amarelo, respectivamente.

\section{CONCLUSÕES}

A concentração de $60 \%$ de biofertilizante bovino nas três épocas de avaliação aumentou os teores foliares de N, P e $\mathrm{K}$ e reduziu os teores de Ca e $\mathrm{Mg}$ em plantas de figo nos diferentes ambientes de cultivo.

As plantas de figo adubadas com 0 biofertilizante bovino estavam supridas em $\mathrm{N}$, $\mathrm{P}$ e K, e deficiente em Ca e Mg durante as três épocas de avaliação nos diferentes ambientes de cultivo.

\section{REFERÊNCIAS BIBLIOGRÁFICAS}


BOARETTO, A. E.; RAIJ, B. V.; SILVA, F. C.; CHITOLINA, J. C.; TEDESCO, M. J.; CARMO, C. A. F. S. Amostragem acondicionamento e preparo de amostras de plantas para análise química. In: Silva, F. C. (Org.). Manual de análises químicas de solos, plantas e fertilizantes. Brasília- DF: Embrapa Informação Tecnológica, 2009. v. 2, p. 59-86.

BRIZOLA, R. M. O.; LEONEL, S.; TECCHIO, M. A.; MISCHAN, M. M. Teores de macronutrientes em pecíolos e folhas de figueira (Ficus carica L.) em função da adubação potássica. Ciência e Agrotecnologia, v. 29, n. 3, p. 610-616, 2005. DOI:org/10.1590/S1413-

70542005000300015.

CARDOSO, A. F.; CHARLO, H. C. O.; ITO, L. A.; CORÁ, J. E.; BRAZ, L. T. Teores foliares de nutrientes em melão rendilhado cultivado em fibra da casca de coco reutilizada. Horticultura Brasileira, v.28, n. 2, p.378384, 2010. http://www.abhorticultura.com.br/eventosx/tr abalhos/ev_4/a3107_t5044_comp.pdf.

CAVALCANTE, L. F.; DINIZ, A. A.; SANTOS, L. C. F.; REBEQUI, A. M.; NUNES, J. C.; BREHM, M. A. S. Teores foliares de macronutrientes em quiabeiro cultivado sob diferentes fontes e níveis de matéria orgânica. Semina, v. 31, n. 1, p. 19-28, $2010 . \quad$ DOI:org/10.5433/16790359.2010v31n1p19.

CAVALCANTE, L. F.; PEREIRA, W. E.; CURVÊLO, C. R. S.; NASCIMENTO, J. A. M.; CAVALCANTE, I. H. L. Estado nutricional de pinheira sob adubação orgânica do solo. Revista Ciência Agronômica, v. 43, n. $\quad 3, \quad$ p. $\quad 579-588, \quad 2012$. http://ccarevista.ufc.br/seer/index.php/ccarevi sta/article/view/1622

DALASTRA, I. M.; PIO, R.; CAMPAGNOLO, M. A.; DALASTRA, G. M.; CHAGAS, E. A.; GUIMARÃES, V. F. Épocas de poda na produção de figos verdes
'Roxo de Valinhos' em sistema orgânico na região oeste do Paraná. Revista Brasileira de Fruticultura, v.31, n.2, p.447-453, 2009. DOI: org/10.1590/S010029452009000200019.

EMPRESA BRASILEIRA DE PESQUISA AGROPECUÁRIA (EMBRAPA). Manual de métodos de análises de solo. 2. ed. Rio de Janeiro: Ministério da Agricultura e do Abastecimento,1997. $212 \mathrm{p}$.

EMPRESA BRASILEIRA DE PESQUISA AGROPECUÁRIA - EMBRAPA. Sistema brasileiro de classificação de solos. 3.ed. Brasília, 2013. 353 p.

LEONEL, S.; TECCHIO, M. A. Épocas de poda e uso da irrigação em figueira 'Roxo de Valinhos' na região de Botucatu, SP. Bragantia, v. 69, n. 3, p. 571- 580, 2010. DOI:org/10.1590/S000687052010000300008 .

LEONEL, S., DAMATTO JUNIOR, E. R.; Efeitos do esterco de curral na fertilidade do solo, no estado nutricional e na produção da figueira. Revista Brasileira de Fruticultura, v. 30, n. 2, p. 534-539, 2008. DOI:org/10.1590/S010029452008000200046.

MACEDO, J. P. S. Adubação nitrogenada, potássica e orgânica sobre o crescimento e nutrição do figo Roxo de Valinhos na Paraíba. Paraíba: Universidade Federal da Paraíba 2008. 55 p. Dissertação Mestrado.

MALAVOLTA, E.; VITTI, G. C.; OLIVEIRA, S. A. Avaliação do estado nutricional das plantas: princípios e aplicações. Piracicaba: Potafos, 1997. 319 p.

MARROCOS, S. T. P.; NOVO JÚNIOR, J.; GRANGEIRO, L. C.; AMBROSIO, M. M. Q.; CUNHA, A. P. A. Composição química e microbiológica de biofertilizantes em diferentes tempos de decomposição. Revista 
Caatinga, v. 25, n. 4, p. 34-43, 2012. https://periodicos.ufersa.edu.br/index.php/caat inga/article/view/2557/pdf_24.

MARTINS, L. M.; CRUZ, M. C. M.; CARVALHO, R. P.; FAGUNDES, C. P.; GRAZZIOTTI, P. H. Absorção de nutrientes por mudas de amoreira preta cultivadas em substrato orgânico. Revista Agrarian, v.6, n.19, p.16-21, 2013. http://ojs.ufgd.edu.br/index.php/agrarian/articl e/view/1835/1371.

MENEZES, E. F.; CAVALCANTE, L. F.; MESQUITA, F. D.; CAMPOS, V. B.; DANTAS, T. A. G. Composição mineral do maracujazeiro amarelo em resposta ao biofertilizante bovino e cloreto de potássio no solo. Revista Brasileira de Ciências Agrárias, v.7, n.2, p.260-268, 2012. DOI: 10.5039/agraria.v7i2a1637.

MOREIRA, R. A.; RAMOS, J. D.; ARAÚJO, N. A.; MARQUES, V. B.; MELO, P. C. Produtividade e teores de nutrientes em cladódios de pitaia vermelha utilizando-se adubação orgânica e granulado bioclástico. Revista Brasileira de Ciências Agrárias, v.7, suplemento, p.714-719, 2012. DOI:10.5039/agraria.v7isa1551.

PENTEADO, S. R. Adubação Orgânica: Compostos orgânicos e biofertilizantes. Campinas: Edição do autor, 2007.162 p.

REIS, L. S.; SOUZA, J. L.; AZEVEDO, C. A. V.; LYRA, G. B.; FERREIRA JÚNIOR, R. A.; LIMA, V. L. A. Componentes da radiação solar em cultivo de tomate sob condições de ambiente protegido. Revista Brasileira de Engenharia Agrícola e Ambiental, v.16, n.7, p.739-744, 2012. DOI:org/10.1590/S141543662012000700006.

SANTOS, E. O.; VIANA, T. V. A.; SOUSA, G. G.; CARVALHO, A. C. P. P.; AZEVEDO, B. M. Biomass accumulation and nutrition in micropropagated plants of the banana 'prata catarina' under biofertilisers. Revista
Caatinga, v. 30, n. 4, p. 901 - 911, 2017. https://periódicos.ufersa.edu.br/index.php/caat inga/article/view/6319/pdf.

SANTOS, A. P. G.; VIANA, T. V. A.; SOUSA; G. G.; GOMES-DO-Ó; L. M.; AZEVEDO, B. M.; SANTOS, A. M. Produtividade e qualidade de frutos do meloeiro em função de tipos e doses de biofertilizantes. Revista Brasileira de Horticultura, v.32, n.4, p.409416, 2014. DOI: 10.1590/S0102053620140000400007

SOUSA, G. G.; VIANA, T. V. A.; BRAGA, E. S.; AZEVEDO, B. M.; MARINHO, A. B.; BORGES, F. R. M. Fertirrigação com biofertilizante bovino: Efeitos no crescimento, trocas gasosas e na produtividade do pinhãomanso. Revista Brasileira de Ciências Agrárias, v.8, n.3, p.503-509, 2013. DOI:10.5039/agraria.v8i3a2288.

SILVA, E. T.; BYLLARDT, L. V. B.; GOMES, S.; WOLF, G. D. Comportamento da temperatura do ar sob condições de cultivo em ambiente protegido. Ciências Agrárias Ambientais, v.1, p.51-54. 2003.

http://www2.pucpr.br/reol/pb/index.php/acade mica?dd1=887\&dd99=view\&dd98=pb.

TOMÉ JUNIOR, J. B. Manual para interpretação de análise de solo. Guaíba: RS. Ed.

Agropecuária, 1997. 247 p.

TEDESCO, M. J.; GIANELLO, C.; BISSANI, C. A.; BOHNEN, H.; VOLKWEISS, S. S. Análise de solo, plantas e outros materiais. Porto Alegre: UFRG, 1995. 174 p.

VIANA, T. V. A. SANTOS, A. P. G.; SOUSA, G. G.; PINHEIRO NETO, L. G.; AZEVEDO, B. M.; AQUINO, B. F. Trocas gasosas e teores foliares de NPK em meloeiro adubado com biofertilizantes. Revista Brasileira de Ciências Agrárias, v.8, n.4, p.595-601, 2013. DOI:10.5039/agraria.v8i4a3260. 